\title{
Erratum to: Is cyclophotocoagulation an option in the management of glaucoma secondary to Fuchs' uveitis syndrome?
}

Bogomil Voykov • Christoph Deuter • Manfred Zierhut • Martin Alexander Leitritz • Emmanuella Guenova •

Deshka Doycheva

Published online: 17 April 2014

(C) Springer-Verlag Berlin Heidelberg 2014

Erratum to: Graefes Arch Clin Exp Ophthalmol (2014) 252:485-489

DOI 10.1007/s00417-013-2558-2

The original version of this article inadvertently contained mistake.

The name Emmanuella Guenova-Hötzenecker in the author list is incorrect. The appropriate presenation of such name is given above.

The online version of the original article can be found at http://dx.doi.org/10. 1007/s00417-013-2558-2.

B. Voykov $(\bowtie) \cdot$ C. Deuter $\cdot$ M. Zierhut $\cdot$ M. A. Leitritz $\cdot$

D. Doycheva

Centre for Ophthalmology, University Hospital Tübingen,

Schleichstr. 12-16, 72076 Tübingen, Germany

e-mail: bogomil.voykov@med.uni-tuebingen.de

E. Guenova

Department of Dermatology, University Hospital Zürich, Zürich,

Switzerland

D. Doycheva

Knappschaft Eye Hospital, Sulzbach, Germany 